\title{
Emerging treatments for essential thrombocythemia
}

This article was published in the following Dove Press journal:

Journal of Blood Medicine

I December 201 I

Number of times this article has been viewed

\section{Steven Okoli \\ Claire Harrison}

Department of Haematology, Guy's and St Thomas' NHS Foundation Trust, Great Maze

Pond, London, UK
Correspondence: Claire Harrison Department of Haematology, Guy's and St Thomas' NHS Foundation Trust, Great Maze Pond, London SEI9RT, UK

Tel +44 207। 882742

Fax +44 297। 882728

Email claire.harrison@gstt.nhs.uk
Abstract: In 1934, Epstein and Goedel used the term hemorrhagic thrombocythemia to describe a disorder characterized by permanent elevation of a platelet count to more than three times normal, hyperplasia of megakaryocytes, and the tendency for venous thrombosis and spontaneous hemorrhage. Over the last 75 years, and particularly in the past 6 years, major progress has been made in our understanding of essential thrombocythemia (ET) and its pathogenesis with the identification of the highly prevalent JAK-2 V617F and other mutations. Current management of this condition is based upon historical data and with treatments that have not changed significantly for nearly two decades. This study discusses this and recent progress, highlighting exciting new data with old and new drugs, as well as which patients in particular should be evaluated for these new therapies.

Keywords: essential thrombocythemia, interferon, JAK inhibitor

\section{Introduction}

Essential thrombocythemia (ET) is the most common of the myeloproliferative neoplasms (MPNs), with an incidence estimated at 1.5-2 individuals per 100,000 annually. ${ }^{1}$ The median age at diagnosis is $50-55$ years, although the diagnosis is increasingly being made in younger adults. In fact, a second peak at about 30 years has been noted. The majority of those diagnosed at this age are female, raising important management issues in this group at child-bearing age. ET is characterized by a variable rate of thrombotic and hemorrhagic complications, and long-term risk of myelofibrotic and/or leukemic transformation. ${ }^{2}$

The optimal management of ET remains controversial, due to the heterogeneity of the disorder and limitations - particularly the side effects - of current therapeutic modalities. The discovery of JAK-2 V617F mutation, an activating tyrosine kinase mutation commonly found in MPNs, ie, polycythemia vera (PV), ET, and primary myelofibrosis (PMF), has created intense interest in developing novel agents to target JAK-2 in the treatment of MPNs. ${ }^{3}$ This mutation, located within the autoinhibitory pseudokinase domain of JAK2, results in constitutive activation of this key tyrosine kinase that is associated with most hemopoietic growth factor receptors. More than $95 \%$ of PV patients carry the mutation, compared to about half of all those with ET or PMF, albeit at different levels of allele burden. ${ }^{4}$ Although the JAK-2 V617F mutation is the most common mutation associated with ET, other mutations also lead to constitutive JAK-2 activity, eg, MPLW515L/K mutations in the MPL receptor resides on exon 10 account for a further $4 \%$ of ET patients. ${ }^{5}$ 
This paper reviews the current therapies and their limitations and discusses novel agents as well as future therapeutic strategies available in the management of ET.

\section{Achieving a diagnosis}

There are a large number of potential causes of thrombocytosis which need to be excluded when making a diagnosis of ET. In 1986, the first diagnostic criteria for ET were proposed by the Polycythemia Vera Study Group. ${ }^{6}$ The criteria were most recently modified by the World Health Organization in 2008, in light of the discovery of the JAK2 V617F mutation. ${ }^{7}$ The BCSH have recently proposed a modification of these diagnostic criteria, as shown in Table 1, acknowledging difficulties in the recognition of specific histological features associated with ET and early primary myelofibrosis (PMF). ${ }^{8,9}$

\section{Who do we currently treat and what with?}

ET presents in children and adults of all ages. The risks associated with the disease as well as potential side effects of therapies have led to risk stratification being developed to guide treatment philosophy. The aims of current treatment

Table I Diagnostic criteria for essential thrombocythemia (ET) ${ }^{37}$

\section{WHO diagnostic criteria as proposed in $2008^{7}$}

Diagnosis requires meeting all four criteria

I. Sustained platelet count $\geq 450 \times 10^{\%} / \mathrm{L}$ during the work-up period

2. Bone marrow biopsy specimen showing proliferation mainly of the megakaryocytic lineage with increased numbers of enlarged, mature megakaryocytes; no significant increase or left-shift of neutrophil granulopoiesis or erythropoiesis

3. Not meeting WHO criteria for PV, PMF, CML, MDS, or other myeloid neoplasm

4. Presence of an acquired pathogenic mutation (JAK2 or MPL)

Modified WHO criteria as proposed by $\mathrm{BCSH}^{8}$

\begin{tabular}{|c|c|}
\hline Diagnostic criterion & $\begin{array}{l}\text { To make a diagnosis of } E T \text { requires } \\
\text { either } A I+A 2 \text { or } A I+A 3-A 5\end{array}$ \\
\hline $\mathrm{Al}$ & Sustained platelet count $>450 \times 10^{9} / \mathrm{L}$ \\
\hline $\mathrm{A} 2$ & $\begin{array}{l}\text { Presence of an acquired pathogenic } \\
\text { mutation (JAK2 or MPL) }\end{array}$ \\
\hline A3 & $\begin{array}{l}\text { No other myeloid malignancy, especially } \\
\text { PV, PMF, CML, or MDS }\end{array}$ \\
\hline A4 & $\begin{array}{l}\text { No reactive cause for thrombocytosis and } \\
\text { normal iron stores }\end{array}$ \\
\hline A5 & $\begin{array}{l}\text { Bone marrow aspirate and trephine } \\
\text { histology showing increased } \\
\text { megakaryocytes number with prominent } \\
\text { large hyperlobated forms; reticulin is } \\
\text { generally not increased ( } \geq 2 \text { on a } 0-4 \text { scale) }\end{array}$ \\
\hline
\end{tabular}

Abbreviations: BCSH, The British Committee for Standards in Haematology; $\mathrm{CML}$, chronic myeloid leukemia; MDS, myelodysplastic syndrome; PMF, primary myelofibrosis; PV, polycythemia vera; WHO, World Health Organization. are to reduce thrombotic and hemorrhagic complications; minimize the risk of transformation to acute myeloid leukemia and post ET myelofibrosis; control symptoms and avoid iatrogenic harm due to drug-related toxicity or adverse event. It is notable that cure is not a treatment aim; this illustrates the limitations of current therapies.

Risk stratification is currently based upon factors known to be associated with the risks of thrombosis or hemorrhage. The risk factors for hemorrhage are a history of diseaserelated hemorrhage or excessive thrombocytosis, while the well-established risk factors for thrombotic complications in ET are age $>60$ years and a history of previous thrombosis (reviewed in Harrison et $\mathrm{al}^{8}$ ). Patients with these risk factors would probably benefit from cytoreductive therapy and would currently be regarded as high-risk patients. As yet, there is little international consensus regarding other risk categorizations, in particular whether there is a true intermediate-risk group and how to account for established vascular risk factors such as smoking. ${ }^{10}$

There is an increasing body of evidence that other factors should be considered during risk stratification and future algorithms. These include leukocytosis; both the presence and quantity of the JAK2 V617F mutation; and possibly the presence of bone marrow fibrosis. In 1998, Lengfelder et al reported a retrospective study of 143 patients, comparing white cell counts at presentation, and noted an elevated white cell count was an indicator of poorer outcome. ${ }^{11}$ More recent work suggests that leukocytosis above $15 \times 10^{9} / \mathrm{L}$ is associated with increased thrombotic risk. ${ }^{12}$ It is clear that further work is necessary to establish leukocytosis as a more reliable determinant of those at risk of thrombosis. Several studies have assessed the impact of the JAK2 V617F mutation upon thrombotic risk in ET patients. These studies variably identified those patients who were JAK2 V617F-positive to have a higher risk of thrombotic complications, a result that has been confirmed in a recent meta-analysis. ${ }^{13}$ Increasing mutant allele quantity also correlated with a higher frequency of arterial thrombosis at diagnosis, although the evidence for this is limited and few patients with ET have substantial allele burdens. ${ }^{4}$ In an analysis of the MRC PT1 trial, cohort reticulin grade was also correlated with thrombosis. ${ }^{14}$ In the future, consideration of these factors could improve risk stratification.

\section{High-risk patients}

Current therapeutic agents for ET are summarized in Table 2 and response criteria from the European LeukemiaNet in Table $3 .{ }^{15}$ Unfortunately, there are relatively few large-scale 
Table 2 Currently available therapies in management of essential thrombocythemia (ET)

\begin{tabular}{|c|c|c|c|c|}
\hline Agent & Mode of action & Adverse effects & $\begin{array}{l}\text { Ability to moderate } \\
\text { AML or post-ET MF }\end{array}$ & $\begin{array}{l}\text { Effects upon } \\
\text { malignant clone }\end{array}$ \\
\hline Aspirin & COX inhibition & Hemorrhage, peptic ulceration & No & None \\
\hline Hydroxycarbamide & $\begin{array}{l}\text { Ribonucleotide reductase } \\
\text { inhibitor }\end{array}$ & $\begin{array}{l}\text { Gl symptoms, cytopenias, } \\
\text { mucocutaneous ulceration, } \\
\text { pigmentation }\end{array}$ & $\begin{array}{l}\text { Potentially leukemogenic. } \\
\text { May reduce post ET MF }\end{array}$ & Probably none \\
\hline Anagrelide & Imidazo-quinazinolone & $\begin{array}{l}\text { Headache, palpitations, fluid } \\
\text { retention }\end{array}$ & $\begin{array}{l}\text { Increased post ET MF } \\
\text { compared with } \\
\text { hydroxycarbamide }\end{array}$ & None \\
\hline Interferon $\alpha$ & $\begin{array}{l}\text { Naturally occurring } \\
\text { cytokine }\end{array}$ & $\begin{array}{l}\text { Gl symptoms, depression, } \\
\text { flu-like symptoms, thyroid disease }\end{array}$ & Unknown & May reduce \\
\hline Busulfan & $\begin{array}{l}\text { Alkylating agent metabolic } \\
\text { competitor of pyrimidine } \\
\text { bases }\end{array}$ & $\begin{array}{l}\text { Gl symptoms, liver dysfunction, } \\
\text { pulmonary fibrosis, seizures }\end{array}$ & $\begin{array}{l}\text { Leukemogenic } \\
\text { May affect post ET MF }\end{array}$ & Probably none \\
\hline Pipobroman & Alkylating agent & Pancytopenia & $\begin{array}{l}\text { Leukemogenic } \\
\text { May affect post ET MF }\end{array}$ & Probably none \\
\hline Phosphorus 32 & Irradiation & Pancytopenia & $\begin{array}{l}\text { Leukemogenic } \\
\text { May affect post ET MF }\end{array}$ & Probably none \\
\hline
\end{tabular}

Abbreviations: AML, acute myeloid leukemia; ET MF, essential thrombocythemia myelofibrosis; GI, gastrointestinal.

randomized controlled studies in ET to inform the use of these agents. These are summarized in Table 4 and include the 'Bergamo study', ${ }^{16}$ MRC PT-1 high risk arm, ${ }^{17}$ and the Anahydret trial. ${ }^{18}$ The current agent of choice is hydroxycarbamide $(\mathrm{HC})$ but there are concerns over the increased

Table 3 European LeukemiaNet criteria for response in ET

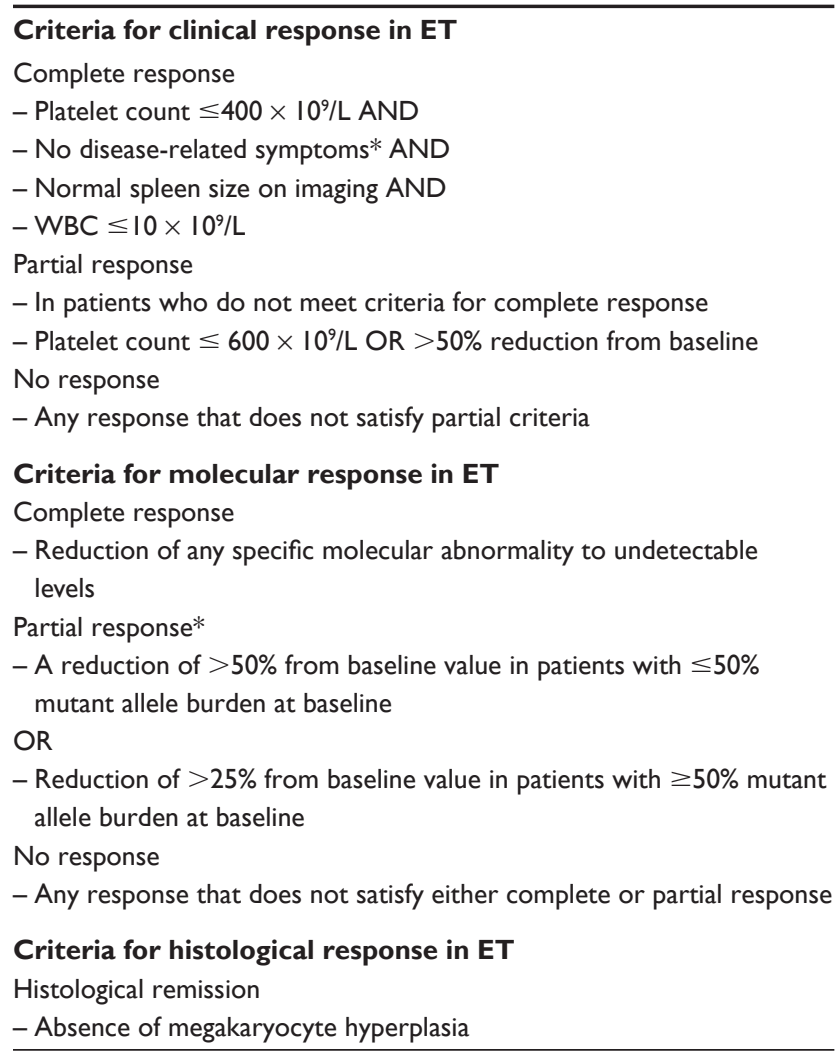

Note: *Applies only to patients with a baseline value of mutant allele burden $>10 \%$. Abbreviation: ET, essential thrombocythemia. risk of leukemic transformation in patients treated with this agent. Clinical studies attempting to address this issue have returned conflicting results, often confounded by factors such as small numbers, the use of multiple therapies, lack of proper controls, retrospective data collection, and relatively short follow-up. Another confounding factor is that transformation may occur anyway, in the absence of cytoreductive therapy. The most recent data from the Swedish cancer registry suggests no excess risk of leukemia ${ }^{19}$ and contradicts long-term follow-up of French PV patients, ${ }^{20}$ suggesting appreciable risk, albeit in a related disease with no untreated controls. For these reasons anagrelide and interferon are often considered for young patients, and interferon may well emerge as a treatment of choice (as discussed below) but this will require further evaluation. ${ }^{21}$

An area of concern, where good-quality evidence is currently lacking, is the management of those patients who are refractory or resistant to HC. This will be discussed in detail as this group of patients has limited therapeutic options and would likely benefit from future therapies. Criteria for resistance and intolerance have been developed by the European LeukemiaNet, ${ }^{22}$ as seen in Table 5. Options for management in the face of $\mathrm{HC}$ resistance would include adjusting therapeutic targets (for example to a platelet count of $600 \times 10^{9} / \mathrm{L}$ ) or switching to an alternative agent either alone or in combination. In this regard, and for the management of intolerance, it is important to consider that when $\mathrm{HC}$ is used with or succeeded by agents with leukemogenic potential, such as busulfan, this will significantly potentiate the leukemogenicity of either agent alone. ${ }^{23}$ For this reason 
Table 4 Comparison of pivotal studies in essential thrombocythemia

\begin{tabular}{|c|c|c|c|}
\hline & Anahydret trial & PT-I trial & Bergamo trial \\
\hline \multirow{2}{*}{ Diagnosis } & WHO criteria (200I) & PVSG criteria & Cortelazzo $\mathrm{S}$ et $\mathrm{al}^{28}$ \\
\hline & Central review of histology & Diagnosis by treating physician & \\
\hline \multirow[t]{2}{*}{ Patients } & High-risk & High-risk & High-risk \\
\hline & Treatment naive & Treated or untreated & Treated or untreated \\
\hline $\begin{array}{l}\text { Median age (years): anagrelide/HC/ } \\
\text { control }\end{array}$ & $58 / 56 /-$ & $61 / 62 /-$ & $-/ 56 / 58$ \\
\hline \multirow[t]{2}{*}{ Patient numbers } & I 22 (ANAG) & 405 (ANAG/aspirin) & $67(\mathrm{HC})$ \\
\hline & $136(\mathrm{HC})$ & 404 (HC/aspirin) & 69 (control) \\
\hline Follow-up & 539 & 2653 & 257 \\
\hline \multicolumn{4}{|l|}{ (patient years) } \\
\hline \multicolumn{4}{|l|}{ Total events } \\
\hline Arterial thrombosis & 10 & 54 & $2 / 11$ \\
\hline Venous thrombosis & 7 & 17 & $0 / 3$ \\
\hline Hemorrhage & 6 & 30 & 7 \\
\hline Transformation to MF & 0 & 21 & $?$ \\
\hline Conclusion & ANAG non-inferior & $\mathrm{HC} /$ aspirin superior to ANAG/aspirin & $\begin{array}{l}\text { HC superior to control, } \\
\text { aspirin not controlled }\end{array}$ \\
\hline
\end{tabular}

Abbreviations: ANAG, anagrelide; HC, hydroxycarbamide; PVSG, Polycythaemia Vera Study Group; WHO, World Health Organization.

non-leukemogenic agents such as interferon- $\alpha$ or anagrelide are considered more appropriate in this setting.

\section{Low- and intermediate-risk patients}

Two ongoing randomized trials will further inform the management of ET. The first is the National Cancer Research Institute study for intermediate-risk patients (defined here as age 40-60 years with no high-risk features). This is a randomized comparison of $\mathrm{HC}$ plus aspirin with aspirin alone. It is expected to report in 2012. Until the results of this study are known, treatment guidelines for this intermediate-risk group of patients remain poorly evidence based. The National Cancer Research Institute study for low-risk patients (defined as age $<40$ years with no high-risk features), is also open and is an observational study with recommended management of

Table 5 European LeukemiaNet criteria for resistance or intolerance to hydroxycarbamide in essential thrombocythaemia ET

Any ONE of

Resistance

I. Platelet count $>600 \times 10^{\circ} / \mathrm{L}$ after 3 months of at least $2 \mathrm{~g} /$ day of hydroxycarbamide $(2.5 \mathrm{~g} /$ day in patients with a body weight $>80 \mathrm{~kg})$, OR

2. Platelet count $>400 \times 10^{9} / \mathrm{L}$ and WBC count $<2.5 \times 109 / \mathrm{L}$ at any dose of hydroxycarbamide, OR

3. Platelet count $>400 \times 10^{9} / \mathrm{L}$ and hemoglobin $<10 \mathrm{~g} / \mathrm{dL}$ at any dose of hydroxycarbamide

OR

Intolerance

4. Presence of leg ulcers or other unacceptable mucocutaneous manifestations at any dose of hydroxycarbamide, OR

5. Hydroxycarbamide-related fever aspirin only. Support for this strategy of aspirin for the majority of patients with ET in the absence of clear contraindications comes from the ECLAP study, a randomized comparison of aspirin with no antiplatelet therapy in PV patients at low or intermediate risk of vascular events. ${ }^{24}$ This demonstrated a significantly reduced risk of vascular events in patients randomized to receive aspirin, and the benefits of aspirin came at no increased risk of major hemorrhage. A recent retrospective review of 300 low-risk ET patients in Spanish centers where antiplatelet agents (mostly aspirin) were given at the discretion of investigators suggested that aspirin protected patients with cardiovascular risk factors against arterial events and those with the JAK2 V617F mutation against venous events. There is, however, an underlying risk of hemorrhage for those patients with platelet counts over $1000 \times 10^{9} / \mathrm{L}^{25}$ This study suggests in the future that recommendations for aspirin in ET should be reviewed. However, as it also recorded a death from PE in one patient, it highlights that low risk does not equate to no risk due to disease.

\section{Limitations of current treatments and treatment strategies}

Current therapies and risk stratification for ET as discussed above have changed little over the past two decades, reflecting a lack of understanding regarding pathogenesis of the disease that could then be used to design newer therapies. The clinical heterogeneity of the condition and its low prevalence has also hampered progress. The description of the JAK2 V617F mutation and others in these patients has reinvigorated this field and resulted in significant advances. 
Current treatments as discussed above include active monitoring only and low-dose aspirin alone or in combination with cytoreductive therapies. Therapies are generally used alone rather than in combination, which is an unusual feature in hematological malignancies. None of these current strategies addresses or directly targets either the malignant clone, evolution of the disease, or symptoms suffered by patients that affect quality of life. With regard to symptoms, an international collaboration using a specifically developed and validated quality of life tool (myeloproliferative neoplasmssymptom assessment form MPN-SAF ${ }^{26}$ demonstrates that many patients have burdensome symptoms, such as fatigue and pruritis, that significantly impact upon their lives. Both malignant clone and symptoms targets are relevant in evaluating newer treatments and have indeed been incorporated into treatment response criteria, which have been established through the European LeukemiaNet and are summarized in Table $3 .{ }^{15}$ There are also difficulties in determining clonal remission and challenges in establishing highly sensitive assays for the JAK2 V617F mutation that yield reproducible results at a highly sensitive level, but work is ongoing to achieve this.

A difficulty in assessing treatments and their ability to reduce or slow secondary events in ET like leukemia or myelofibrosis, is that such events are an infrequent occurrence in common clinical practice. The group of patients who are $\mathrm{HC}$ refractory or resistant, however, are a good target for evaluating newer therapies in this regard. For example, Spanish investigators have retrospectively evaluated European LeukemiaNet criteria for clinical response and then resistance/ intolerance to $\mathrm{HC}$ in $166 \mathrm{ET}$ patients treated with $\mathrm{HC}$ for a median of 4.5 years. ${ }^{27}$ Overall, 134 patients achieved a complete clinicohematological response and 25 a partial response. Of note, patients achieving a complete response (CR), even if sustained during the entire follow-up, did not benefit from a lower incidence of thrombosis or an improved survival, suggesting that clinicohematological response may not be the best target for novel therapies. Regarding resistance or intolerance, 33 patients met at least one of the criteria defining resistance $(n=15)$ or intolerance $(n=21)$ to HC. Fifteen cases developed anemia with thrombocytosis, which was associated with a high incidence of myelofibrosis and death from any cause. Other definitions of resistance were less useful. Future trials should be designed with these important results in mind.

\section{Novel agents \\ Simple statins}

The impact of conventional risk factors for atherosclerosis, including hyperlipidemia and hypertension, has been assessed in MPN with variable results. Limited work, however, has been specifically performed in ET. ${ }^{29}$ Recent recommendations for the management of atherosclerosis suggest that this patient group may benefit from aggressive risk management with the use of antihypertensives and a statin, where appropriate. An issue and concern is when the statin or alternative agent might be appropriate and what the treatment target should be. There is a strong rationale for the use of statins in these disorders, bearing in mind the pleomorphic effects of statins with regard to apoptosis, angiogenesis and perhaps the most recent being the observation that JAK2 is present in 'lipid rafts' in the cell membrane. ${ }^{30} \mathrm{~A}$ randomized study in this setting to address the utility of agents such as statins is unlikely but mechanistic support from well-designed cell line or animal model-based experiments, followed by observational studies, could be of benefit.

\section{PEGylated interferon alpha (INF $\alpha)$}

Recently, two Phase II studies have evaluated the role of the PEGylated interferon alpha 2a isoform of IFN (Pegasys, Roche); their results are also supported by cohorts of patients reported in abstract form. The first, called PVN1, was a multicenter Phase II trial involving only PV patients but still of relevance. Here Kiladjian and coworkers prospectively evaluated clinical, hematological, and molecular response. ${ }^{31}$ At 12 months, all 37 evaluable patients had hematologic response, including 94.6\% CRs. Only three patients (8\%) had stopped treatment. After the first year, 35 patients remained in hematologic CR, including five who had stopped Pegasys. Sequential samples for V617F monitoring, available in 29 patients, showed a percentage V617F decrease in 26 (89.6\%). Median percentage V617F decreased from $45 \%$ to $22.5 \%, 17.5 \%, 5 \%$, and $3 \%$ after $12,18,24$, and 36 months, respectively. Molecular CR (JAK2 V617F undetectable) was achieved in seven patients, lasting from 6 to 18 months, and persisted after Pegasys discontinuation in five patients. No vascular event was recorded. The results confirm the hypothesis that IFN- $\alpha$ preferentially targets the malignant clone in PV and show that JAK2 V617F allele burden may be useful in monitoring minimal residual disease in PV patients. However, in a recent update, this group did show that whilst the JAK2 V617F clone was reduced by Pegasys, the TET- 2 mutant clones were apparently not affected. ${ }^{32}$

The second study was conducted by the MD Anderson group and included both PV $(\mathrm{n}=40)$ and ET patients $(\mathrm{n}=39) .{ }^{33}$ Here the median time that had elapsed from diagnosis was longer, and these patients had previously received at least one other cytoreductive drug, therefore 
representing a different clinical and biological cohort. Despite this, excellent hematological response rates were observed: $81 \%$ (including $78 \% \mathrm{CR}$ ), and $92 \%$ (including $86 \% \mathrm{CR}$ ) in PV and ET, respectively. Major molecular responses were achieved in $30 \%$ and $13 \%$ of PV and ET patients, respectively, with $13 \%$ of complete molecular responses in both diseases. Tolerance was also better than reported with other forms of IFN since only $10 \%$ of treatment discontinuation was due to Pegasys toxicity. No patients suffered grade 4 toxicity, and grade 3 toxicities were reported in a small number of patients only and only in the following categories: pain, fatigue, dyspnea, and pruritis.

The studies of Pegasys in PV and ET described above both report high levels of hematologic complete response rates; good tolerance of the drug particularly when started at low dose; and most significantly a clear selective effect on the disease clone in a significant proportion of patients, including complete molecular responses. This data has also been reported in abstract form for groups of patients managed outside of the context of a clinical trial. ${ }^{34}$ This data suggests that Pegasys may be effective when other therapies have failed or not been tolerated and that it may challenge the position of $\mathrm{HC}$ as a first-line therapy. However this will require large randomized trials with comprehensive evaluation for long-term side-effects as the side-effect profile for interferon is more adverse than that for $\mathrm{HC}$ and there is little evidence to support the contention that Pegasys (or indeed other PEGylated interferons) are better tolerated than conventional interferon, especially in a disease that (unlike the hepatitis field) requires long-term therapy. Two such trials are currently being launched internationally: a Phase III randomized study of $\mathrm{HC}$ vs Pegasys in newly diagnosed high-risk ET and PV and a Phase II study of Pegasys in HC resistant or refractory patients to include a cohort of patients with abdominal vein thrombosis.

\section{JAK inhibitors}

A significant number of JAK inhibitors are now at varying stages of clinical evaluation with most data available for patients with myelofibrosis. ${ }^{35}$ Most of these agents are well tolerated and have a clinically measurable benefit for these patients, particularly in reducing symptomatic splenomegaly and constitutional symptoms such as pruritis or fatigue. Two large Phase III trials in myelofibrosis have recently been completed confirming the benefit of these agents in reducing splenomegaly and controlling symptoms when compared to placebo or physician choice of standard therapies. ${ }^{36,37}$ As yet, there is no conclusive evidence that these agents either significantly reduce the JAK2 V617F mutant allele burden or alter the natural history of the disease.

There is, however, emerging data supporting the ability of JAK inhibitors to control both myeloproliferation and symptoms in patients with PV and ET. In these disorders, however, an ability to prevent thrombosis, affect the risk of transformation to post-ET or post-PV MF or indeed leukemia is also desirable.

Moliterno and colleagues treated 39 patients (12 ET, 27 PV), all had high-risk disease and prior therapies, with CEP 701 (Cephalon $\left.{ }^{\circledR}\right) .{ }^{38}$ However, marked gastrointestinal side effects occurred and whilst there were responses in splenomegaly, pruritis, and phlebotomy requirements (after 6 months), treatment was not associated with a reduction in either leukocytosis or thrombosis, as five thrombotic events occurred on treatment.

In the study using INC18424 (now termed Ruxolitinib ${ }^{\circledR}$ ) in $39 \mathrm{ET}$ and $34 \mathrm{PV}$ patients, there were similar rates of reduction of splenomegaly and symptom scores. All patients had leukocyte counts below $10 \times 10^{9} / \mathrm{L}$ and $41 \%$ achieved a CR with platelets less than $400 \times 10^{9} / \mathrm{L}$ and no thrombotic events have been reported. ${ }^{39}$ Specifically with regard to ET, $49 \%$ achieved normal platelet counts and $79 \%$ achieved $<600 \times 10^{9} / \mathrm{L}$ or a $\geq 50 \%$ reduction as of last follow-up visit. Thirteen of 14 subjects with baseline platelet counts $>1000 \times 10^{9} / \mathrm{L}$ have achieved a $>50 \%$ reduction. Importantly this study demonstrated marked and sustained benefit of this agent upon quality of life concerns, in particular pruritus but also fatigue. Ruxolitinib therapy was recently demonstrated in two Phase III trials to be of benefit in PMF patients when compared to placebo or best available therapy (ie, standard of care) in reduction of spleen volume and quality of life. ${ }^{36,37}$ Data with regard to survival advantage or transformation to leukemia is awaited with interest. This agent appears to have only modest benefit in targeting the malignant clone specifically. In PV patients refractory or intolerant of $\mathrm{HC}$ a trial termed 'RESPONSE' is currently underway to assess the utility of Ruxolitinib ${ }^{\circledR}$ compared with best available therapy (http://www.responsetrial.com; or http://clinicaltrials.gov/ct2/show/NCT01243944).

Further results from larger studies with longer follow-up are required for JAK inhibitor therapy, but it appears that these drugs have the relatively unique contribution of addressing the patient symptoms. An initial impression is that in order to attain clonal response or complete remission it is likely to be necessary to combine these agents with another therapeutic modality. PEGylated interferon is an obvious choice, although to be able to escalate dose whilst 
ameliorating the consequent anemia or thrombocytopenia, agents such as erythropoietin may be required.

\section{Histone deacetylase inhibitors}

Interest in histone deacetylase inhibitors such as panobinostat, vorniostat, and givinostat in patients with ET and PV is growing as a single therapy or in combination with other therapies. Histone-deacetylases (HDACs) are enzymes involved in the remodeling of chromatin, and have a key role in the epigenetic regulation of gene expression. In addition, the activity of non-histone proteins can be regulated through HDAC-mediated hypoacetylation. Altered expression of HDAC has been reported in MPN patients that, in addition to their pleiotropic actions, makes these drugs an interesting option for clinical trials in ET. In recent years, inhibition of HDACs has emerged as a potential strategy to reverse aberrant epigenetic changes associated with cancer. ${ }^{40}$ Givinostat $^{\mathrm{R}}$ (ITF2357; Italfarmaco S.p.A., Cinisello Balsamo, Italy) is a synthetic class I and II HDAC inhibitor with potent anti-proliferative and pro-apoptotic activity against several hematological malignancies. ${ }^{41}$ In addition to these anti-tumor features, preclinical studies of Givinostat also showed that it could inhibit the production/release of several cytokines, including tumor necrosis factor- $\alpha$ (TNF- $\alpha$ ), interleukin (IL)1b, IL-6, IL-12, c-interferon (IFNc), and vascular endothelial growth factor (VEGF) by neoplastic as well as endothelial and mesenchymal cells. ${ }^{42}$

Based on these properties, Givinostat was evaluated in the treatment of JAK2 V617F positive PV, ET, and PMF. ${ }^{43}$ Givinostat was given orally for 24 weeks at a starting dose of $50 \mathrm{mg}$ twice daily with a median treatment duration of 20 weeks. Reasons for treatment discontinuation were disease progression $(n=6)$, grade 2 thrombocytopenia $(n=1)$, psychiatric symptoms $(n=1)$, and withdrawn consent $(n=2)$. A dose reduction was applied in ten patients while a temporary interruption occurred in 15. Among $13 \mathrm{PV} / \mathrm{ET}$ patients, one complete, six partial, and four no responses were documented at study end. Two patients went off-study, prematurely, and concomitant $\mathrm{HC}$ was required in four patients. Strikingly, pruritus disappeared in most patients and reduction of splenomegaly was observed in $75 \%$ of PV/ET patients. Reverse transcription polymerase chain reaction identified a modest trend to reduction of the JAK2 V617F allele burden.

A notable feature of HDAC is that they do not appear to be as well tolerated as conventional ET therapy such as HC. However, their striking effect upon symptoms and potentially allele burden means they would perhaps be re-evaluated at either a different dose or perhaps in combination with other agents. Rambaldi et al describes co-administration with $\mathrm{HC}^{43}$ and in a cell-line model, Wang and colleagues ${ }^{30}$ describe that combined treatment with panobinostat and the JAK2 inhibitor TG101209 attenuates JAK2 V617F levels and signaling and exerts synergistic cytotoxic effects against human myeloproliferative neoplastic cells. They demonstrated that panobinostat treatment depletes the autophosphorylation, expression, and downstream signaling of JAK2 V617F and disrupted the chaperone association of JAK2 V617F with heat shock protein 90, thus promoting proteasomal degradation of JAK2 V617F. Combined treatment with panobinostat and TG101209 further depleted JAK/STAT signaling and synergistically induced apoptosis of JAK2 V617F expressing cell lines. ${ }^{30}$ These observations provide a rationale for cotreatment with HDAC, heat shock protein 90, as well as JAK inhibitors.

\section{Conclusions}

The management of ET has previously been problematic from the perspective of achieving a timely certain diagnosis and the absence of robust evidence-based clinical management guidelines. This is a relatively rare condition viewed by many as indolent. Until recently there have been no major advances in our understanding of disease biology or pathogenesis to inform treatment options and strategies. Recent advances in our understanding of the molecular pathogenesis of these disorders and data from clinical trials has improved this. Evidence is now growing to support a reconsideration of the classification of these disorders from essentially those based upon clinical and morphological descriptions to molecularand clinical-based classification based upon prospective correlative analyses from large numbers of patients. There have been further refinements and better agreement upon what the indications for cytoreductive therapy are. Yet we still lack agents which achieve our therapeutic goals and robust data about long-term safety (particularly leukemogenicity) of commonly used agents such as HC. Confusion also continues regarding who should receive antiplatelet agents, most commonly low-dose aspirin, and indeed when treatment with agents such as statins may be required or beneficial.

We are gaining a better understanding of which patients are in most need of treatment and are perhaps beginning to assess true remission as a treatment target. To this end, interest in interferons has been rejuvenated with data suggesting that PEGylated interferons may induce high levels of clinical and hematologic remission and also in some patients a molecular complete response. A robust clinical study in newly diagnosed high-risk ET is required to evaluate the comparison 
between HC and Pegasys. Patients with HC intolerance or resistance provide an important highly relevant group to study more experimental agents, such as JAK2 inhibitors.

The success of imatinib in chronic myeloid leukemia as yet has not been reproduced using JAK2 inhibitors in ET, illustrating important differences in the pathobiology of the JAK2 V617F mutation and BCR/ABL translocation. These newer agents deliver treatment against symptoms producing a response not gained with other agents, and these benefits are both unique and important for patients. Additional novel therapeutics such as HDAC inhibitors either alone or in combination are also currently being explored.

Lastly, this paper also discussed the relevance of treatment targets and strategies including whether we should now be switching our strategy to try to deliver a complete response or cure for all patients. This seems a goal for the future but a more pressing one is the need to identify robustly the toxicity of current treatments, even including aspirin and $\mathrm{HC}$, and to identify which treatments address patient needs with regard to quality of life.

\section{Disclosure}

The authors declare no conflicts of interest in this work.

\section{References}

1. Johansson P. Epidemiology of the myeloproliferative disorders polycythemia vera and essential thrombocythemia. Semin Thromb Hemost. 2006;32(3):171-173.

2. Vardiman JW, Thiele J, Arber DA, et al. The 2008 revision of the World Health Organization (WHO) classification of myeloid neoplasms and acute leukemia: rationale and important changes. Blood. 2009;114(5):937-951.

3. James C, Ugo V, Casadevall N, Constantinescu SN, Vainchenker W. A JAK2 mutation in myeloproliferative disorders: pathogenesis and therapeutic and scientific prospects. Trends Mol Med. 2005;11(12): 546-554.

4. Vannucchi AM, Antonioli E, Guglielmelli P, Pardanani A, Tefferi A. Clinical correlates of JAK2V617F presence or allele burden in myeloproliferative neoplasms: a critical reappraisal. Leukemia. 2008;22(7): 1299-1307.

5. Beer PA, Campbell PJ, Scott LM, et al. MPL mutations in myeloproliferative disorders: analysis of the PT-1 cohort. Blood. 2008;112(1):141-149.

6. Murphy S, Iland H, Rosenthal D, Laszlo J. Essential thrombocythemia: an interim report from the Polycythemia Vera Study Group. Semin Hematol. 1986;23(3):177-182.

7. Tefferi A, Thiele J, Vardiman JW. The 2008 World Health Organization classification system for myeloproliferative neoplasms: order out of chaos. Cancer. 2009;115(17):3842-3847.

8. Harrison CN, Bareford D, Butt N, et al. Guideline for investigation and management of adults and children presenting with a thrombocytosis. Br J Haematol. 2010;149(3):352-375.

9. Wilkins BS, Erber WN, Bareford D, et al. Bone marrow pathology in essential thrombocythemia: interobserver reliability and utility for identifying disease subtypes. Blood. 2008;111(1):60-70.
10. Barbui T, Barosi G, Birgegard G, et al. Philadelphia-negative classical myeloproliferative neoplasms: critical concepts and management recommendations from European LeukemiaNet. J Clin Oncol. 2011; 29(6):761-770.

11. Lengfelder E, Hochhaus A, Kronawitter U, et al. Should a platelet limit of $600 \times 10(9) / 1$ be used as a diagnostic criterion in essential thrombocythaemia? An analysis of the natural course including early stages. Br J Haematol 1998;100(1):15-23.

12. Carobbio A, Antonioli E, Guglielmelli P, et al. Leukocytosis and risk stratification assessment in essential thrombocythemia. J Clin Oncol. 2008;26(16):2732-2736.

13. Dahabreh IJ, Zoi K, Giannouli S, Zoi C, Loukopoulos D, Voulgarelis M. Is JAK2 V617F mutation more than a diagnostic index? A metaanalysis of clinical outcomes in essential thrombocythemia. Leuk Res. 2009;33(1):67-73.

14. Campbell PJ, Bareford D, Erber WN, et al. Reticulin accumulation in essential thrombocythemia: prognostic significance and relationship to therapy. J Clin Oncol. 2009;27(18):2991-2999.

15. Barosi G, Birgegard G, Finazzi G, et al. Response criteria for essential thrombocythemia and polycythemia vera: result of a European LeukemiaNet consensus conference. Blood. 2009;113(20): 4829-4833.

16. Cortelazzo S, Finazzi G, Ruggeri M, et al. Hydroxyurea for patients with essential thrombocythemia and a high risk of thrombosis. N Engl J Med. 1995;332(17):1132-1136.

17. Harrison CN, Campbell PJ, Buck G, et al. Hydroxyurea compared with anagrelide in high-risk essential thrombocythemia. $N$ Engl J Med. 2005;353(1):33-45.

18. Gisslinger H, Gotic M, Holowiecki J, et al. Final Results of the ANAHYDRET-Study: Non-Inferiority of Anagrelide Compared to Hydroxyurea in Newly Diagnosed WHO-Essential Thrombocythemia Patients. ASH Annual Meeting Abstracts. 2008;112(11):661.

19. Bjorkholm M, Derolf AR, Hultcrantz M, et al. Treatment-related risk factors for transformation to acute myeloid leukemia and myelodysplastic syndromes in myeloproliferative neoplasms. J Clin Oncol. 2011;29(17):2410-2415.

20. Kiladjian J-J, Chevret S, Dosquet C, Fenaux P, Chomienne C, Rain J-D. Long-Term Outcome in Polycythemia Vera (PV): Final Analysis of a Randomized Trial Comparing Hydroxyurea (HU) to Pipobroman (Pi). ASH Annual Meeting Abstracts. 2008;112(11):1746.

21. Kiladjian JJ, Mesa RA, Hoffman R. The renaissance of interferon therapy for the treatment of myeloid malignancies. Blood. 2011; 117(18):4706-4715.

22. Barosi G, Birgegard G, Finazzi G, et al. A unified definition of clinical resistance and intolerance to hydroxycarbamide in polycythaemia vera and primary myelofibrosis: results of a European LeukemiaNet (ELN) consensus process. Br J Haematol. 2010;148(6):961-963.

23. Sterkers Y, Preudhomme C, Lai JL, et al. Acute myeloid leukemia and myelodysplastic syndromes following essential thrombocythemia treated with hydroxyurea: high proportion of cases with $17 \mathrm{p}$ deletion. Blood. 1998;91(2):616-622.

24. Marchioli R, Finazzi G, Landolfi R, et al. Vascular and neoplastic risk in a large cohort of patients with polycythemia vera. J Clin Oncol. 2005;23(10):2224-2232.

25. Alvarez-Larran A, Cervantes F, Pereira A, et al. Observation versus antiplatelet therapy as primary prophylaxis for thrombosis in low-risk essential thrombocythemia. Blood. 2010;116(8):1205-1210; quiz 387.

26. Scherber R, Dueck AC, Johansson P, et al. The Myeloproliferative Neoplasm Symptom Assessment Form (MPN-SAF): International Prospective Validation and Reliability Trial in 402 patients. Blood. 2011;118(2):401-408.

27. Hernandez-Boluda JC, Alvarez-Larran A, Gomez M, et al. Clinical evaluation of the European LeukaemiaNet criteria for clinicohaematological response and resistance/intolerance to hydroxycarbamide in essential thrombocythaemia. Br J Haematol. 2011;152(1):81-88. 
28. Cortelazzo S, Viero P, Finazzi G, D’Emilio A, Rodeghiero F, Barbui T. Incidence and risk factors for thrombotic complications in a historical cohort of 100 patients with essential thrombocythemia. J Clin Oncol. 1990;8(3):556-562.

29. Besses C, Cervantes F, Pereira A, et al. Major vascular complications in essential thrombocythemia: a study of the predictive factors in a series of 148 patients. Leukemia. 1999;13(2):150-154.

30. Wang Y, Fiskus W, Chong DG, et al. Cotreatment with panobinostat and JAK2 inhibitor TG101209 attenuates JAK2V617F levels and signaling and exerts synergistic cytotoxic effects against human myeloproliferative neoplastic cells. Blood. 2009;114(24):5024-5033.

31. Kiladjian JJ, Cassinat B, Chevret S, et al. Pegylated interferon-alfa-2a induces complete hematologic and molecular responses with low toxicity in polycythemia vera. Blood. 2008;112(8):3065-3072.

32. Kiladjian JJ, Masse A, Cassinat B, et al. Clonal analysis of erythroid progenitors suggests that pegylated interferon alpha-2a treatment targets JAK2V617F clones without affecting TET2 mutant cells. Leukemia. 2010;24(8):1519-1523.

33. Quintas-Cardama A, Kantarjian H, Manshouri T, et al. Pegylated interferon alfa-2a yields high rates of hematologic and molecular response in patients with advanced essential thrombocythemia and polycythemia vera. J Clin Oncol. 2009;27(32):5418-5424.

34. Roy L, Ianotto JC, Guilhot J, et al. Pegylated Interferon Alpha-2a Therapy for Patients with High Risk Essential Thrombocytemia: a Retrospective Analysis on 59 Patients. On Behalf of the French Intergroup of Myeloproliferative Disorders (FIM). ASH Annual Meeting Abstracts. 2010;116(21):1974.

35. Tibes R, Mesa RA. Myeloproliferative neoplasms 5 years after discovery of JAK2V617F: what is the impact of JAK2 inhibitor therapy? Leuk Lymphoma. 2011;52(7):1178-1187.

36. Verstovsek S, Mesa RA, Gotlib JR, et al. Results of COMFORT-I, a randomized double-blind phase III trial of JAK $1 / 2$ inhibitor INCB18424 (424) versus placebo (PB) for patients with myelofibrosis (MF) [abstract]. J Clin Oncol. 2011;29(Suppl):Abst 6500.
37. Harrison CN, Kiladjian J, Al-Ali HK, et al. Results of a randomized study of the JAK inhibitor ruxolitinib (INC424) versus best available therapy (BAT) in primary myelofibrosis (PMF), postpolycythemia vera-myelofibrosis (PPV-MF) or post-essential thrombocythemia-myelofibrosis (PET-MF) [abstract]. J Clin Oncol. 2011; 29(Suppl):Abst LBA6501.

38. Moliterno AR, Hexner E, Roboz GJ, et al. An Open-Label Study of CEP-701 in Patients with JAK2 V617F-Positive PV and ET: Update of 39 Enrolled Patients. ASH Annual Meeting Abstracts. 2009;114(22):753.

39. Verstovsek S, Passamonti F, Rambaldi A, et al. Durable Responses with the JAK1/JAK2 Inhibitor, INCB018424, In Patients with Polycythemia Vera (PV) and Essential Thrombocythemia (ET) Refractory or Intolerant to Hydroxyurea (HU). ASH Annual Meeting Abstracts. 2010;116(21):313.

40. Skov V, Larsen TS, Thomassen M, et al. Increased gene expression of histone deacetylases in patients with Philadelphia-negative chronic myeloproliferative neoplasms. Leuk Lymphoma. 2011.

41. Leoni F, Fossati G, Lewis EC, et al. The histone deacetylase inhibitor ITF2357 reduces production of pro-inflammatory cytokines in vitro and systemic inflammation in vivo. Mol Med. 2005;11(1-12):1-15.

42. Furlan A, Monzani V, Reznikov LL, et al. Pharmacokinetics, safety and inducible cytokine responses during a phase 1 trial of the oral histone deacetylase inhibitor ITF2357 (givinostat). Mol Med. 2011;17(5-6):353-362.

43. Rambaldi A, Dellacasa CM, Finazzi G, et al. A pilot study of the Histone-Deacetylase inhibitor Givinostat in patients with JAK2V617F positive chronic myeloproliferative neoplasms. Br J Haematol. 2010;150(4):446-455

\section{Publish your work in this journal}

The Journal of Blood Medicine is an international, peer-reviewed, open access, online journal publishing laboratory, experimental and clinical aspects of all topics pertaining to blood based medicine including but not limited to: Transfusion Medicine; Blood collection, Donor issues, Transmittable diseases, and Blood banking logistics; Immunohematology; Artificial and alternative

\section{Dovepress}

blood based therapeutics; Hematology; Biotechnology/nanotechnology of blood related medicine; Legal aspects of blood medicine; Historical perspectives. The manuscript management system is completely online and includes a very quick and fair peer-review system. Visit http://www.dovepress.com/ testimonials.php to read real quotes from published authors. 